\section{Avaliação de políticas públicas de segurança alimentar e combate à fome no período 1995-2002. 4 - Programa Nacional de Alimentação Escolar}

\author{
Evaluation of food security and anti-hunger public \\ policies in Brazil, 1995-2002. 4 - National School \\ Nutrition Program
}

Leonor Maria Pacheco Santos ${ }^{1}$

Sandra Maria Chaves dos Santos ${ }^{2}$ Luciana Alaíde Alves Santana ${ }^{3}$ Flavia Conceição Santos Henrique 4 Roseanne Porto Dantas Mazza 2 Ligia Amparo da Silva Santos 2 Lílian Silva dos Santos 2

\section{Introdução}

This study evaluated the Brazilian National School Nutrition Program from a structureprocess-results perspective. The methodology involved document research and a case study in 45 counties and 73 schools in the State of Bahia, including program manager interviews and household questionnaires involving 3,367 children (7-14 years of age). Relating to program structure, the study analyzed the evolution of normative instruments and some infrastructure aspects. Managers reported problems with the installations for preparing and distributing meals in 28\% of the counties. Decentralization to the county (municipal) level was present in 93\% of cases and to the school level in about 20\%; however, nearly $70 \%$ of the schools received the food supplies directly. Although Social Control Councils were created, members were not always chosen democratically. Acceptability of the meals was good, as expected considering the widespread poverty in the target population. Overall program coverage was high (95\%), but $77 \%$ of schoolchildren in the interior and $39 \%$ in the capital city did not receive meals every day. So far, irregular school meal distribution has frustrated the program's aspirations to become a universal social policy and ensure a basic right for children.

Food Security; Students; Program Evaluation
A Constituição Federal de 1988, no seu artigo 208, incisos IV e VII, reconheceu a alimentação dos alunos da rede pública como um direito, garantindo o atendimento universal aos escolares por meio de um programa de alimentação, sem qualquer discriminação. A intervenção pública brasileira neste campo, no entanto, tem uma história bastante longa: o Programa Nacional de Alimentação Escolar (PNAE) é o programa social mais antigo do país na área de segurança alimentar.

Durante os seus 50 anos de existência e após várias mudanças de nome, de vinculação institucional e de estratégias, o PNAE manteve seu foco na suplementação alimentar aos escolares de escolas públicas ou filantrópicas conveniadas. O programa justifica-se pela oportunidade de garantir aos escolares acesso a uma melhor alimentação, de forma permanente e, assim, contribuir para o melhor desempenho escolar e para a redução da evasão. Dessa forma, pode-se considerar que o PNAE atua na promoção da segurança alimentar para esse grupo social prioritário.

O marco inicial do PNAE ocorreu em 1955, quando foi assinado o Decreto $n^{o}$. 37.106, instituindo a Campanha de Merenda Escolar, subordinada ao Ministério da Educação 1. Até 1960 os alimentos distribuídos eram obtidos por doação de instituições internacionais como o Fundo das Nações Unidas para Infância e Adolescência (UNICEF) e Ministério da Agricultura dos Esta- 
dos Unidos, por meio do programa Alimentos para Paz 2,3 .

Essa intervenção, no entanto, passa a assumir uma dimensão de política social de âmbito nacional como parte integrante do II PRONAN (Programa Nacional de Alimentação e Nutrição) implementado a partir de 1976 pelo Instituto Nacional de Alimentação e Nutrição. Sua finalidade era oferecer uma refeição que complementasse parcialmente as necessidades calóricas diárias de escolares do 1o grau e pré-escolares da rede pública de ensino. A Campanha de Alimentação Escolar, como era identificado na década de 70 , foi o programa de maior abrangência dentre todos os que integraram o PRONAN, chegando a alcançar, em 1979, 14 milhões de escolares 4.

A característica marcante do programa nas suas fases iniciais foi a utilização de alimentos formulados, primeiramente doados, e, a partir dos anos 70, alimentos formulados produzidos no Brasil. O controle financeiro e gestão centralizada do programa, aliados ao forte lobby das indústrias de alimentos, contribuíram para essa situação.

A partir de 1983 a operação do programa passou à responsabilidade da Fundação de Assistência ao Educando (FAE), que foi extinta em 1997. O PNAE então passa a ser coordenado pela Secretaria Executiva do Fundo Nacional para o Desenvolvimento da Educação (FNDE).

A partir da década de 80 o Programa de Alimentação Escolar incorporou a descentralização como um elemento norteador de sua implementação ${ }^{5}$, cabendo destacar a municipalização e a participação comunitária ${ }^{6}$. Contudo, a integração com o capital industrial de alimentos foi conservada e a participação dos alimentos formulados permaneceu marcante 2 .

A municipalização do programa foi instituída inicialmente de modo experimental, via celebração de convênios com o Ministério da Educação 7. Destaca-se que o PNAE alcançou bons resultados entre os programas nacionais submetidos ao processo descentralizador. Com importante estrutura de incentivos, a municipalização do programa passou de um cenário de 300 municípios respondendo por sua operação em 1993, para 1.500 já em 1994. Ao final de 1995, 3.380 municípios haviam assumido a gestão do programa dentre os cerca de 5 mil municípios então existentes no país 8 . No ano de 2005, segundo dados oficiais, o PNAE envolveu recursos da ordem de R $\$ 1,5$ bilhão e alcançou 37 milhões de escolares, o que dá a dimensão de sua importância no cenário da intervenção social em segurança alimentar no Brasil 9.

Este estudo objetivou avaliar o PNAE no período 1995-2002, buscando reconhecer obstáculos e oportunidades que incidem sobre a implementação descentralizada de um programa com tais características.

\section{Metodologia}

A avaliação empreendida do PNAE baseou-se na tríade estrutura - processo - resultado, adaptada para as políticas de segurança alimentar e nutricional, já descrita anteriormente em detalhe 10 e aplicada à avaliação do Programa de Alimentação do Trabalhador 11 e Programa Nacional de Controle da Deficiência de Vitamina A 12. Para guiar a investigação, identificar variáveis e construir instrumentos de coleta de dados foi construída uma matriz específica para o PNAE, conforme previsto na metodologia indicada.

Para a análise da dimensão da estrutura foi considerado o aparato normativo vigente no período em estudo, obtido por pesquisa documental, bem como alguns aspectos da infra-estrutura. As dimensões do processo e do resultado incluíram a análise de dados empíricos do estudo de caso na Bahia, realizado em 1997-1998 (interior) e 2000 (capital), confrontando-os com resultados do estudo Impacto Distributivo do PNAE no Brasil contratado pelo governo federal 13. No tocante ao processo foi analisado o modus operandi do programa, sobretudo o relativo à: modelo de gestão, operacionalização de recursos, adesão a cardápios, constituição e atuação dos Conselhos de Alimentação Escolar. Na dimensão de resultado foram analisadas a cobertura e focalização do PNAE, a regularidade no fornecimento do benefício, a visibilidade e atuação dos Conselhos de Alimentação Escolar e a opinião de alunos beneficiados (e seus pais) sobre a alimentação escolar.

Os dados utilizados para a análise do PNAE foram obtidos com base em pesquisa documental (dados oficiais do programa), de entrevistas com gestores e de questionários aplicados nos domicílios. A amostra do estudo de caso foi selecionada de modo intencional para representar a população mais pobre do Estado da Bahia. Foram estudados 44 municípios entre os 96 beneficiados pelo Programa Comunidade Solidária, e, em cada um, 20 famílias residentes nas áreas urbanas e 20 nas áreas rurais de mais baixa renda foram selecionadas ao acaso para responder ao questionário. Em Salvador, entrevistaram-se famílias residentes em 38 setores de baixa renda, prioritários para a implantação do Programa Saúde da Família. Assim, foi obtida uma amostra de 2.665 crianças em idade escolar (7 a 14 anos) no interior e de 702 crianças nesta faixa etária na capital. O estudo domiciliar objetivou colher informações sobre a execução do programa, as 
quais foram trianguladas com informações obtidas junto aos gestores locais. A metodologia foi descrita no primeiro artigo desta série 10 .

Planejou-se visitar 88 unidades de ensino fundamental da rede pública que atendessem às comunidades selecionadas, duas em cada município (uma urbana e outra rural), visando a confrontar as informações sobre a execução do PNAE. Tendo em vista as férias escolares e/ou ausência dos responsáveis, 15 unidades estavam fechadas. Assim a amostra correspondeu a 73 escolas, sendo $40(54,8 \%)$ na zona urbana e 33 (45,2\%) na rural. Em Salvador não se realizou a pesquisa nas escolas, pois a maior oferta da rede pública (e privada) impossibilitou a seleção das "escolas de vizinhança" onde as crianças pesquisadas estudavam.

Análises estatísticas de qui quadrado foram realizadas, quando apropriado, adotando o limite de confiança de $95 \%$. O programa empregado foi o Epi Info 2002 (Centers for Disease Control and Prevention, Atlanta, Estados Unidos).

\section{Resultados e discussão}

\section{Dimensão de estrutura}

O PNAE tem como objetivo atender a todas as crianças da rede pública do ensino fundamental (municipal e estadual) e escolas filantrópicas conveniadas, por meio da oferta de uma refeição que responda por pelo menos $15 \%$ das necessidades energético-protéicas diárias do grupoalvo, o que equivale a 350 calorias e 9 gramas de proteína. Pode-se reconhecer que os objetivos e a meta do programa pouco foram alterados ao longo dos anos. No entanto, mudanças no modelo de gestão foram significativas. Para o interesse deste estudo importa destacar a legislação vigente no período em análise:

- Em 1994, com base na Lei $n^{o}$. 8.913, de 12 de julho de 1994, propôs-se a criação do Conselho de Alimentação Escolar nos municípios, visando a participação de membros da comunidade escolar e da sociedade civil nas questões de interesse do programa 5;

- A partir da publicação da Medida Provisória $n^{o}$. 1.784, de 14 de dezembro de 1998, e suas reedições, o FNDE passa a ser o responsável pela transferência automática dos recursos financeiros, abolindo-se a forma convenial ${ }^{14}$. Nesse contexto, o Conselho de Alimentação Escolar ganha ênfase na perspectiva de garantir a implementação adequada do programa nos municípios.

Observa-se então que houve um processo gradativo de passagem de um modelo centralizado para uma implementação descentralizada do pro- grama, com espaço para a participação social em sua gestão, via o Conselho de Alimentação Escolar. Na medida em que se trata de um programa com longa história de centralização, fez-se necessário deixar conviver modelos operacionais diferentes na etapa de transição, sendo que a direção desejada, como para outras políticas sociais, seria a municipalização plena.

Assim, durante algum tempo dois tipos de convênio poderiam ser firmados: entre o FNDE e o estado, ou entre o FNDE e o município. A esfera de governo conveniada, por sua vez, ao receber os recursos, poderia administrá-los ou repassá-los às escolas, que passariam a ser as responsáveis pela compra de gêneros alimentícios e produção da refeição. Em alguns casos também o preparo de alimentos era centralizado para posterior distribuição às unidades escolares. Portanto três modelos de gestão conviveram no período de interesse deste estudo: estadualização, municipalização e escolarização.

O PNAE pode ser entendido como um programa universal para os municípios brasileiros na medida em que inexistem critérios de inclusão ou exclusão de municípios, desde que a documentação requerida e prestação de contas frente ao Tribunal de Contas da União estejam regularizadas. Em relação à clientela alvo, o PNAE também pode ser considerado universalista, na medida em que pressupõe o atendimento de todas as crianças matriculadas em creches, pré-escolas e no ensino fundamental (1a a 8a séries), entre 7 e 14 anos, na rede pública e filantrópica de ensino, sem qualquer discriminação.

O montante de recursos a ser repassado aos municípios, em cada exercício financeiro, correspondia à época do estudo a $\mathrm{R} \$ 0,13$ per capita por aluno matriculado na rede de ensino a ser atendida, conforme dados do censo escolar do ano anterior. Este valor per capita era $\mathrm{R} \$ 0,16$ para aqueles municípios contemplados pelo programa Comunidade Solidária, caso dos 44 municípios estudados na Bahia, de forma a possibilitar a oferta de uma segunda refeição à criança. Conforme a Lei de Diretrizes e Bases da Educação, o número de dias de atendimento corresponde a 200 dias/ano de efetivo trabalho escolar.

Outra orientação refere-se à forma como esses alimentos devem ser distribuídos às escolas. Pode-se optar pela distribuição de refeições preparadas e/ou gêneros alimentícios (produtos básicos, in natura, semiprocessados ou industrializados). A norma recomenda ao gestor a aquisição de alimentos regionais, com o objetivo de respeitar o padrão alimentar local e fortalecer a produção de alimentos e o comércio do município, mas permanece aberta a possibilidade de aquisição de produtos formulados. 
A normalização do programa prevê que a elaboração dos cardápios deve atender aos seguintes aspectos: respeitar os hábitos alimentares de cada localidade considerando a vocação agrícola da região; criar condições para a melhoria da qualidade da alimentação, através da incorporação de $70 \%$ de alimentos básicos (in natura e semi-elaborados); garantir uma dieta mais variada; estimular a formação de bons hábitos alimentares e promoção da educação nutricional no ambiente escolar.

Quanto à estrutura técnico-organizacional necessária para operacionalização, ressalta-se que os recursos repassados da esfera federal para a esfera descentralizada destinam-se exclusivamente à compra de gêneros alimentícios. Para a operacionalização do PNAE cabe ao município arcar com a responsabilidade de montar uma infra-estrutura mínima para preparação das refeições. Os gestores do programa entrevistados nos municípios do interior da Bahia apontaram como principal obstáculo a infra-estrutura insuficiente para preparo das refeições, com freqüência de 28,6\% das respostas. Esse problema praticamente não foi citado na capital. Resultado semelhante foi obtido em outro estudo, no qual foram registrados problemas quanto à infra-estrutura inadequada ao preparo de refeições, particularmente nas escolas localizadas na área rural 8 .

Como visto, a partir de 1994 estabeleceu-se a criação do Conselho de Alimentação Escolar como pré-requisito à adesão ao programa, tendo como finalidade a fiscalização e controle dos recursos e da implementação do Programa no município. O Conselho de Alimentação Escolar tem caráter deliberativo, fiscalizador e de assessoramento. A sua composição ocorre mediante a indicação de representante(s) de cada instância: do Poder Executivo, do Poder Legislativo, dos professores, de pais de alunos, associações de pais e mestres ou entidades similares, e de outro segmento da sociedade local.

\section{Dimensão de processo}

\section{- Modelo de gestão do Programa Nacional de Alimentação Escolar}

O estudo de caso no interior da Bahia revelou que em 41 dos 44 municípios que compuseram a amostra a entidade executora do programa era o município, correspondendo a 93,2\%. Em alguns municípios a gestão do programa estava parcialmente descentralizada, pois conviviam as modalidades escolarizada e centralizada (prefeitura). Na opinião dos gestores ou responsáveis pelo PNAE o modelo escolarizado foi considera- do o melhor, possivelmente pela oportunidade de promover maior proximidade entre gestor e clientela do programa, além da autonomia financeira.

Em 2001 o governo federal contratou um estudo nacional para avaliar o impacto distributivo do PNAE. Foram visitadas 3.809 escolas, nas quais o diretor, a merendeira e um aluno foram entrevistados; a pesquisa incluiu pais de alunos de 324 Conselhos de Alimentação Escolar 13. Os resultados foram apresentados expandidos para o conjunto de 179.658 escolas públicas brasileiras, das quais $63,8 \%$ eram rurais e $36,2 \%$ urbanas. Em relação à unidade executora e modelo de gestão, a pesquisa revelou que em $87,4 \%$ dos casos a entidade convenente era o município e, em 12,6\% o estado, indicando avanço significativo na direção da municipalização.

As mudanças na operação do programa foram, no entanto, lentas. Pesquisa realizada em Campinas, onde a descentralização foi iniciada em 1984, registrou que sete anos após a implantação da municipalização, o cardápio era composto exclusivamente de alimentos formulados, devido à facilidade de preparo, estocagem e distribuição, independente da sua aceitabilidade e irregularidade do recebimento dos gêneros. Somente a partir de 1993 essa situação foi revertida no município 15.

Um estudo sobre experiências de gestão municipalizada do programa em 70 municípios da Região Sudeste do Brasil, realizado nos primeiros anos da década de 90, apontou, como principal resultado da descentralização, a possibilidade de adequar os cardápios aos hábitos alimentares regionais e locais e de garantir a incorporação de produtos in natura ${ }^{8}$. Foi observado ainda, como aspecto positivo citado pela maioria dos municípios estudados, a aquisição dos gêneros alimentícios através dos fornecedores locais, resultando em um reforço para a produção e comércio locais, contribuindo assim para reduzir o custo da alimentação e aumentar a arrecadação de impostos. O aumento do número de dias e a regularidade do atendimento também foram considerados como outros resultados positivos.

Segundo o estudo acima indicado, o processo descentralizador gerou: maior variação do número e do tipo de refeições servidas diariamente aos alunos; aumento do pessoal envolvido e de equipamentos necessários à execução do programa; crescente participação da comunidade na execução do programa; diversificação das fontes de abastecimento do programa; desenvolvimento de novos modelos de controle de qualidade; surgimento da proposta de incorporação do programa às atividades pedagógicas da esco- 
la. Verificou-se, no entanto, que poucos eram os municípios que especificavam o percentual dos requerimentos nutricionais atendidos pela refeição ofertada ${ }^{8}$.

Resultados similares foram encontrados ao se avaliar a implementação do PNAE municipalizado em Cuiabá, Mato Grosso, Brasil, no período de 1993 a 1996. Parte dos resultados corrobora os achados citados acima na direção de uma avaliação positiva dos resultados obtidos com a descentralização; no entanto problemas com a regularidade da oferta do benefício, com o atendimento do preconizado em termos de calorias e proteínas; com a fragilidade do sistema de supervisão e inoperância do controle de qualidade dos gêneros servidos foram observados 16 .

\section{- Modelo operacional de repasse do benefício às escolas}

Os tipos de modelo operacional encontrados no estudo de caso no interior da Bahia em 1997-1998 e na pesquisa nacional realizada em 2001 constam na Tabela 1. A centralização na aquisição dos gêneros alimentícios predominou, tanto nas escolas rurais como nas urbanas, mas pode-se notar algum avanço na escolarização, sobretudo nas situações urbanas.

Outro estudo nacional de avaliação da descentralização de recursos da merenda escolar foi realizado em 1997 aplicando-se um questionário a 5 mil diretores de escolas públicas urbanas. Foram encontrados resultados não muito diferentes: $16 \%$ das escolas recebiam recursos financeiros (escolarização), 72\% das unidades escolares participavam recebendo gêneros alimentícios e em 9\% delas havia centralização na aquisição e preparo de refeições 6 .

Segundo dados do estudo de caso na Bahia, $86 \%$ dos municípios adquiriam produtos para o PNAE no comércio local e/ou cidade vizinha, em consonância com o recomendado na norma, revelando que a descentralização financeira proporcionou movimentação de recursos no município ou na região. Conforme depoimento obtido de um gestor local, Secretário Municipal de Educação, essa compra local é vantajosa também por desonerar o município com gastos relativos ao frete para transporte dos gêneros. Esses dados são compatíveis com outros achados. Foi observado que com a municipalização do programa em Cuiabá, criou-se um sistema de abastecimento local que privilegiou os pequenos produtores, o que favoreceu o crescimento da organização destes sob a forma de associações 16 .

Quanto à modalidade de compra dos produtos alimentícios, os gestores na Bahia informaram que as formas mais utilizadas foram carta convite e compra direta. Essas modalidades possibilitavam que a compra fosse realizada no comércio local, o qual, na grande maioria, não dispõe da documentação legal exigida na Lei de Licitação. Porém uma desvantagem é que o controle da aplicação dos recursos fica reduzido, principalmente na forma de compra direta. Quanto à responsabilidade pela definição dos gêneros alimentícios a serem comprados, os gestores na Bahia citaram o Conselho de Alimentação Escolar com maior freqüência (29\%), seguido pelo secretário de educação/coordenador do programa (24\%).

Modelo operacional de repasse do benefício às escolas adotado pelo Programa Nacional de Alimentação Escolar, segundo a localização, $1997-2001$.

\begin{tabular}{|c|c|c|c|c|c|c|}
\hline \multirow[t]{2}{*}{ Modelo operacional } & \multicolumn{2}{|c|}{ Escolas rurais - Brasil * } & \multicolumn{2}{|c|}{ Escolas urbanas - Brasil * } & \multicolumn{2}{|c|}{ Escolas do interior da Bahia ** } \\
\hline & $\mathbf{n}$ & $\%$ & $\mathrm{n}$ & $\%$ & $\mathrm{n}$ & $\%$ \\
\hline Escolarização & 5.960 & 5,2 & 13.462 & 20,7 & 15 & 20,6 \\
\hline Escolarização parcial & 802 & 0,7 & 3.252 & 5,0 & - & - \\
\hline Centralização da aquisição de gêneros & 105.452 & 92,0 & 44.550 & 68,5 & 50 & 68,5 \\
\hline Centralização da aquisição e preparo & 802 & 0,7 & 2.406 & 3,7 & 6 & 8,2 \\
\hline Terceirização & 229 & 0,2 & 715 & 1,1 & - & - \\
\hline Outros & 1.261 & 1,1 & 715 & 1,1 & 2 & 2,7 \\
\hline Total de escolas & 114.506 & 100,0 & 65.100 & 100,0 & 73 & 100,0 \\
\hline
\end{tabular}

* Dados obtidos em 3.809 escolas, expandidos para o Brasil, Ministério da Educação e do Desporto 13;

** Trabalho de campo (40 escolas urbanas e 33 rurais). 


\section{- Confecção e adesão aos cardápios}

$\mathrm{O}$ adequado planejamento dos cardápios a serem servidos aos escolares, assim como o acompanhamento da execução dos mesmos são importantes para o alcance dos objetivos do programa, na medida em que há um mínimo de aporte nutricional a ser garantido, além de ser este considerado como um instrumento para a formação de bons hábitos alimentares entre os beneficiários.

Nos 44 municípios estudados na Bahia a maioria das escolas recebia alimentos para a produção de refeições, o que resultava em pequena participação destas na definição de que gêneros comprar. Em 26 municípios (59\%) os cardápios adotados eram os mesmos para todas as unidades de ensino, independentemente de sua localização urbana ou rural. A diversidade do cardápio foi referida por $34 \%$ dos gestores entrevistados. Os motivos para diversidade foram muitos, contudo somente $21 \%$ das respostas obtidas consideraram a proposta de adequar o cardápio à realidade local. Observou-se que a aceitabilidade foi o principal critério referido pelos entrevistados nas unidades de ensino para a definição dos cardápios. Pode-se considerar que, com a observação desse critério, buscou-se uma aproximação entre as refeições servidas e o padrão alimentar local. A falta de condições para o preparo de refeições foi uma das razões elencadas para justificar cardápios utilizando alimentos formulados.

$\mathrm{Na}$ pesquisa nacional antes referida, $58,8 \%$ das merendeiras nas escolas urbanas informaram saber sobre a existência do cardápio e declararam segui-lo; porém $25 \%$ não sabiam que existia cardápio e 16,6\% apesar de informarem conhecê-lo, responderam que não o seguiam regularmente 13. Já na área rural esses percentuais foram os seguintes: $38 \%$ conhecem e seguem sempre, $37,8 \%$ não sabem de sua existência e $24,2 \%$ conhecem e não seguem regularmente. Os motivos mais citados para o não seguimento do cardápio foram: (a) falta dos alimentos indicados; (b) desconhecimento do cardápio.

No estudo de Cuiabá registrou-se também uma tentativa de padronização de dez cardápios, elaborados por nutricionistas, os quais foram modificados devido a falhas no abastecimento das escolas; observou-se acompanhamento parcial da execução dos cardápios e alto grau de liberdade das merendeiras para decidir sobre o que preparar e servir aos escolares 16 .

\section{- Constituição e funcionamento dos Conselhos de Alimentação Escolar}

A partir de 1993, a criação do Conselho de Alimentação Escolar passou a ser uma exigência para acesso aos recursos do programa. No estudo de caso na Bahia, o Conselho de Alimentação Escolar estava formalmente instituído em 36 dos 44 municípios (82\%). Nos municípios visitados, 16 dos conselhos foram constituídos entre 1997 e 1998, ou seja, o processo demorou entre 4 e 5 anos, sugerindo o quanto a criação do Conselho de Alimentação Escolar exige condições políticas, institucionais e administrativas locais para ser concretizado. Uma pesquisa de avaliação da atuação dos Conselhos de Alimentação Escolar incluiu 1.378 municípios brasileiros e identificou que entre 1997-1998, 90\% dos municípios haviam criado o órgão colegiado, sendo os maiores percentuais alcançados no Sudeste e os menores no Norte e Nordeste 15.

Quanto ao processo de seleção dos membros do Conselho de Alimentação Escolar, considerando as informações dos conselheiros entrevistados nos 36 municípios estudados onde havia Conselho de Alimentação Escolar, a grande maioria (25 respondentes) não soube informar sobre o processo de composição do conselho. Os depoimentos sugerem limitada transparência e forte presença do executivo municipal na escolha dos representantes. Alguns depoimentos apontaram a inexistência de remuneração como um fator limitante de maior interesse da comunidade pela participação no conselho. Em situações de extrema pobreza e falta absoluta de oportunidades para inserção no mercado, esse comportamento popular é previsível e tem sido encontrado em outros estudos sobre a participação social 16 .

Quanto ao funcionamento do Conselho de Alimentação Escolar e tendo em vista a realização de reuniões, observou-se que entre os municípios estudados na Bahia a maioria dos entrevistados informou haver data marcada para os encontros sistemáticos, mas por outro lado, $14 \%$ referiram que o Conselho de Alimentação Escolar nunca se reuniu após sua constituição. Vários depoimentos obtidos no trabalho de campo reforçaram o caráter episódico das reuniões do Conselho de Alimentação Escolar. Os entrevistados, em geral, identificaram a distância entre as zonas urbana e rural e a falta de disponibilidade de tempo dos membros como fatores limitantes ao pleno funcionamento do conselho.

Quanto às atividades desenvolvidas pelos Conselhos de Alimentação Escolar, a principal referência foi a fiscalização da aplicação de recursos e acompanhamento da distribuição dos 
gêneros (17\%). Destaca-se que 15\% dos entrevistados referiram que o Conselho de Alimentação Escolar não desempenhava nenhuma atividade, estando constituído oficialmente sem atuação concreta junto ao programa. A compra de gêneros alimentícios foi referida por $12 \%$ dos entrevistados.

\section{Dimensão de resultados}

\section{- Acesso ao programa: cobertura, regularidade e focalização}

No Brasil, a evolução do número de alunos que tiveram acesso ao PNAE foi analisada desde o seu início, em 1955, até o ano de 2002, segundo dados oficiais do programa disponibilizados pelo Ministério da Educação (Figura 1). Foi notável a sua expansão, sobretudo após 1979, tanto em termos de número de alunos beneficiados, como de municípios participantes. Não foi possível obter dados sobre o PNAE na Bahia em todo o período estudado. Entre 1999 e 2002, segundo dados do FNDE 19, registrou-se o seguinte número de escolares atendidos pelo programa no estado: 1999
- 3.596.128; 2000 - 3.760.421; 2001 - 3.816.418; e $2002-3.845 .526$.

No estudo de caso realizado em domicílios de baixa renda no interior da Bahia foram identificadas 2.665 crianças e adolescentes na faixa etária de 7-14 anos; destas, 368 estavam fora da escola $(13,8 \%)$ e 1.465 eram potenciais beneficiários do PNAE (Figura 2). Os resultados do estudo em Salvador demonstram um percentual de 5\% de crianças fora da escola, proporção significativamente menor do que a registrada no interior $\left(\chi^{2}=\right.$ 41,15; $\mathrm{p}<0,001)$. Entre os estudantes houve uma maior inserção de alunos na rede privada em Salvador (27\%) do que no interior (1,9\%), e na capital não se registrou criança cursando alfabetização nessa faixa etária. Entre os potenciais beneficiários matriculados em estabelecimentos públicos, 1.465 no interior e 487 em Salvador, a alimentação escolar foi identificada como presente nas escolas por $95,6 \%$ dos primeiros e $96,1 \%$ dos últimos.

A pesquisa nacional anteriormente citada calculou que o índice de cobertura, ou seja, o número de alunos beneficiados em relação ao número de alunos matriculados, em 2001, foi de $94 \%$. Não foram registradas variações importan-

Figura 1

Evolução do número de alunos atendidos e de municípios incluídos no Programa Nacional de Alimentação Escolar. Brasil, 1955-2002.

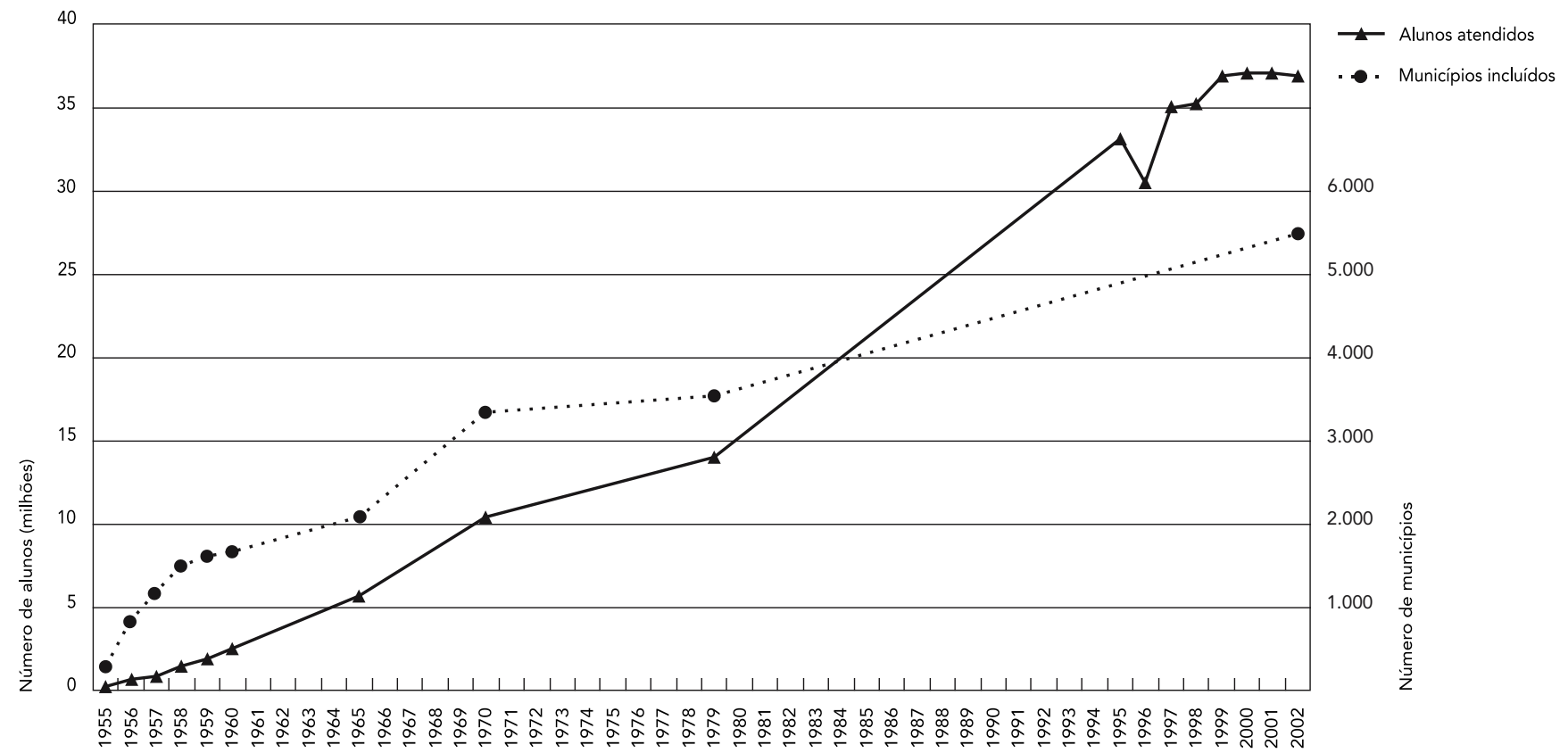

Fonte: Ministério da Educação, Fundo Nacional de Desenvolvimento da Educação. 
Regularidade de oferecimento do benefício do Programa Nacional de Alimentação Escolar na população incluída no estudo de caso. Municípios da Bahia, Brasil, 1997-2000.
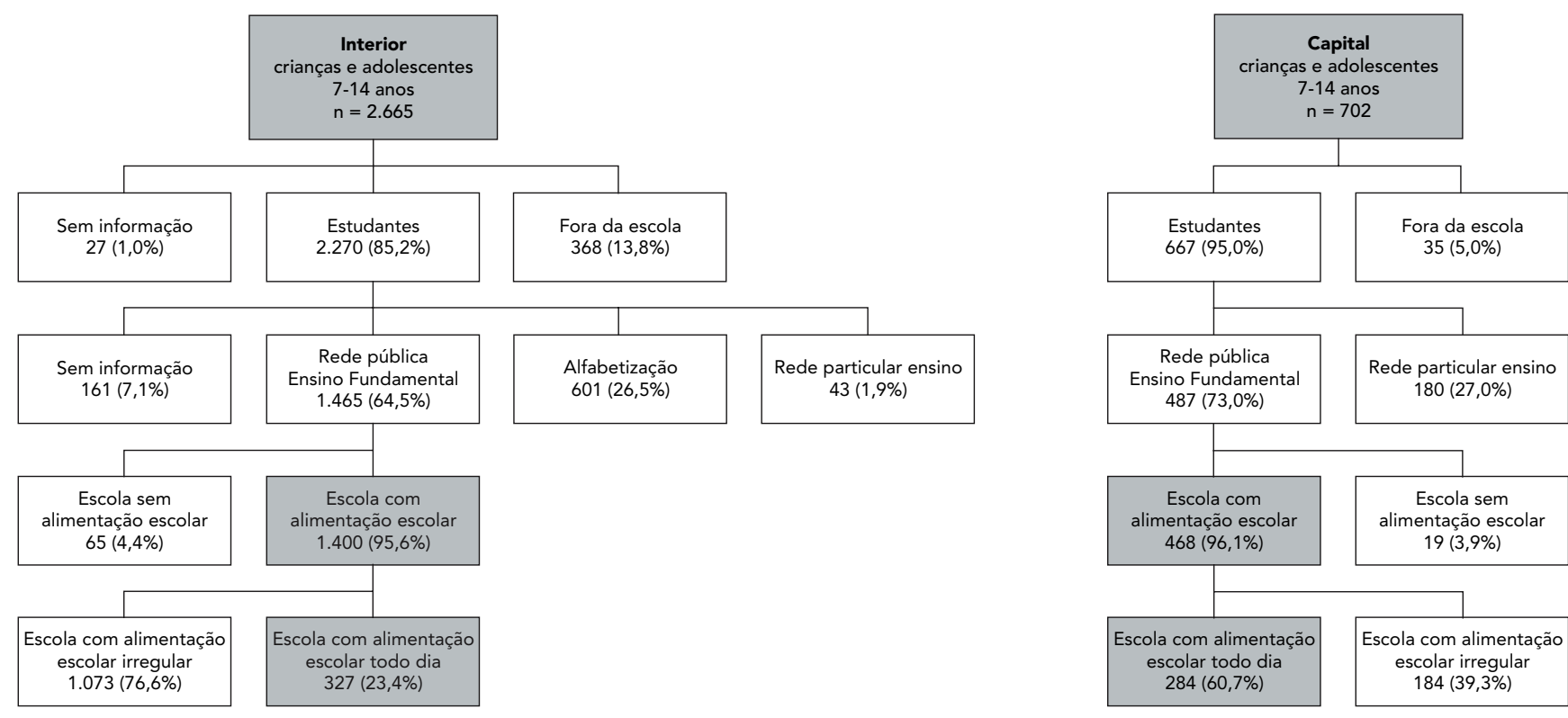

tes segundo a localização rural e urbana, região, porte do município, porte da escola, entidade executora e modelo operacional ${ }^{13}$. Os valores foram muito similares aos registrados no estudo de caso na Bahia.

O expressivo número de alunos atendidos pelo PNAE indica que o programa está próximo de se tornar, de fato, uma política social universal. De outra parte, uma série de problemas operacionais compromete o alcance pleno de seus objetivos. A irregularidade no fornecimento diário da alimentação na escola foi referida por $39,3 \%$ dos alunos em Salvador, quadro significativamente mais favorável do que o do interior do estado, onde $76,6 \%$ dos beneficiários informaram não haver alimentação todos os dias $\left(\chi^{2}=\right.$ 44,15; $\mathrm{p}<0,001$ ) (Figura 2).

Outro estudo, realizado em 1997 junto a 5 mil diretores de escolas públicas, relatou que o programa não sofreu nenhum dia de interrupção em $55 \%$ das escolas urbanas e que foi mais regular nas regiões mais ricas (Sul e Sudeste com $80 \%$ e $75 \%$ sem interrupção, respectivamente) e teve pior desempenho no Nordeste (apenas 27\% sem interrupção) 6 .

$\mathrm{Na}$ pesquisa nacional de 2001, segundo informações fornecidas pelos gestores, foram registrados atrasos no repasse de recursos em cerca de um quarto das escolas, tanto urbanas como rurais; já o atraso na entrega de alimentos foi maior e apresentou maior diferencial rural/ urbano, sendo $39,8 \%$ nas escolas rurais e $30,7 \%$ nas urbanas (Figura 3). Esse fato foi responsável pela interrupção da Alimentação Escolar, atingindo a expressiva proporção de 33,9\% das escolas rurais que recebiam gêneros alimentícios. Os resultados do estudo nacional permitiram estimar, considerando a margem de erro da pesquisa, que 45 mil escolas sofreram interrupção no fornecimento do benefício sob a forma de alimentos em 2001, sendo cerca de $37 \mathrm{mil} \mathrm{ru-}$ rais e 8 mil urbanas ${ }^{13}$. Observa-se então que na modalidade de repasse de recursos existe menor chance de atraso e, além disto, quando ocorrem, acarretam menos dias sem alimentação escolar. No entanto, para uma ou outra modalidade, a existência de um sistema de monitoramento da execução do programa nas escolas seria uma estratégia importante para garantir a regularidade.

No conjunto dos 44 municípios do interior incluídos no estudo de caso na Bahia, um terço dos gestores entrevistados referiu irregularidade no repasse dos recursos. Em todas as escolas 
Regularidade do benefício no Programa Nacional de Alimentação Escolar segundo a situação da escola e o tipo de repasse previsto no modelo de gestão. Brasil, 2001.

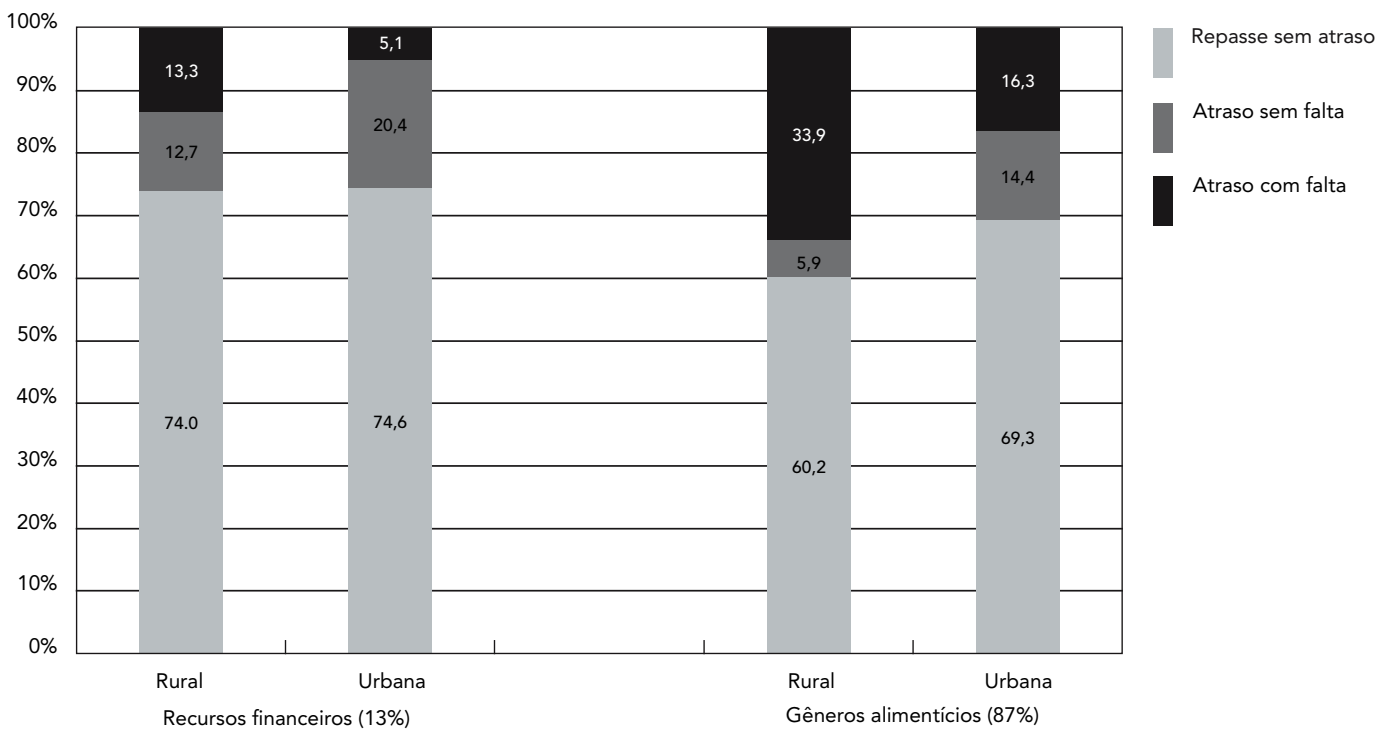

Fonte: Ministério da Educação e do Desporto 13.

com atraso foi relatada interrupção na Alimentação Escolar, sendo que na metade dos casos a irregularidade na oferta persistiu por um ou até dois semestres letivos. Cabe ressaltar a enorme diferença na irregularidade de fornecimento da Alimentação Escolar informada pelos gestores (33\%) e pelos alunos (76,6\%). Os resultados sobre interrupção de alimentação escolar da Bahia estão bem acima do encontrado na pesquisa nacional.

No estudo de caso foi possível observar a insatisfação de diversos atores envolvidos com o atraso no repasse de recursos financeiros: nas escolas estaduais a direção era pressionada a fornecer o benefício frente à divulgação de que receberia recursos para tanto; a prefeitura era culpabilizada tanto por alunos, pais e mestres pela não oferta do benefício; e os escolares permaneciam sem a refeição que, em alguns casos, poderia representar a única oportunidade de se alimentar diariamente.

A focalização do PNAE foi analisada entre os escolares estudados nos 44 municípios do interior da Bahia (Figura 4). Foi registrado um maior percentual de crianças de famílias classificadas na linha de indigência na zona rural $(68,1 \%)$ e, em contraposição, a proporção de classificados como não-pobres foi maior nas zonas urbanas dos municípios (32,5\%), indicando uma situação de maior risco social na zona rural, como vem sendo discutido na literatura sobre a pobreza no Brasil. Apesar da alta taxa de cobertura anteriormente citada, observou-se que na área urbana o percentual de escolas sem Alimentação Escolar aumentava significativamente à medida que a situação de pobreza se agravava: $1,1 \%$ entre os não-pobres, $3,1 \%$ entre os pobres e $6,1 \%$ entre os indigentes $\left(\chi^{2}=10,54 ; p=0,005\right)$. O mesmo não se observou nas escolas rurais $\left(\chi^{2}=0,14 ; \mathrm{p}=0,934\right)$.

O estudo Impacto Distributivo do PNAE no Brasil 13 analisou também o consumo dos alimentos na escola por outros que não a população alvo - professores, funcionários e comunidade em geral. $\mathrm{O}$ vazamento, ou destinação de alimentos para outros que não escolares, é um indicativo de focalização inadequada. A pesquisa nacional encontrou que em $62 \%$ das escolas da zona rural e $55 \%$ das urbanas, os alimentos do PNAE eram compartilhados por outras pessoas. A maior citação de outros comensais foi de $97 \%$ professores, $90 \%$ funcionários e $10 \%$ pessoas da comunidade (múltiplas respostas admitidas). Pesquisa anterior, realizada em 1997 pelo mesmo grupo, já havia detectado essa irregularida- 
Cobertura e focalização do Programa Nacional de Alimentação Escolar na população incluída no estudo de caso, segundo zona de residência e linha de pobreza. Municípios do interior da Bahia, Brasil, 1997-1998.

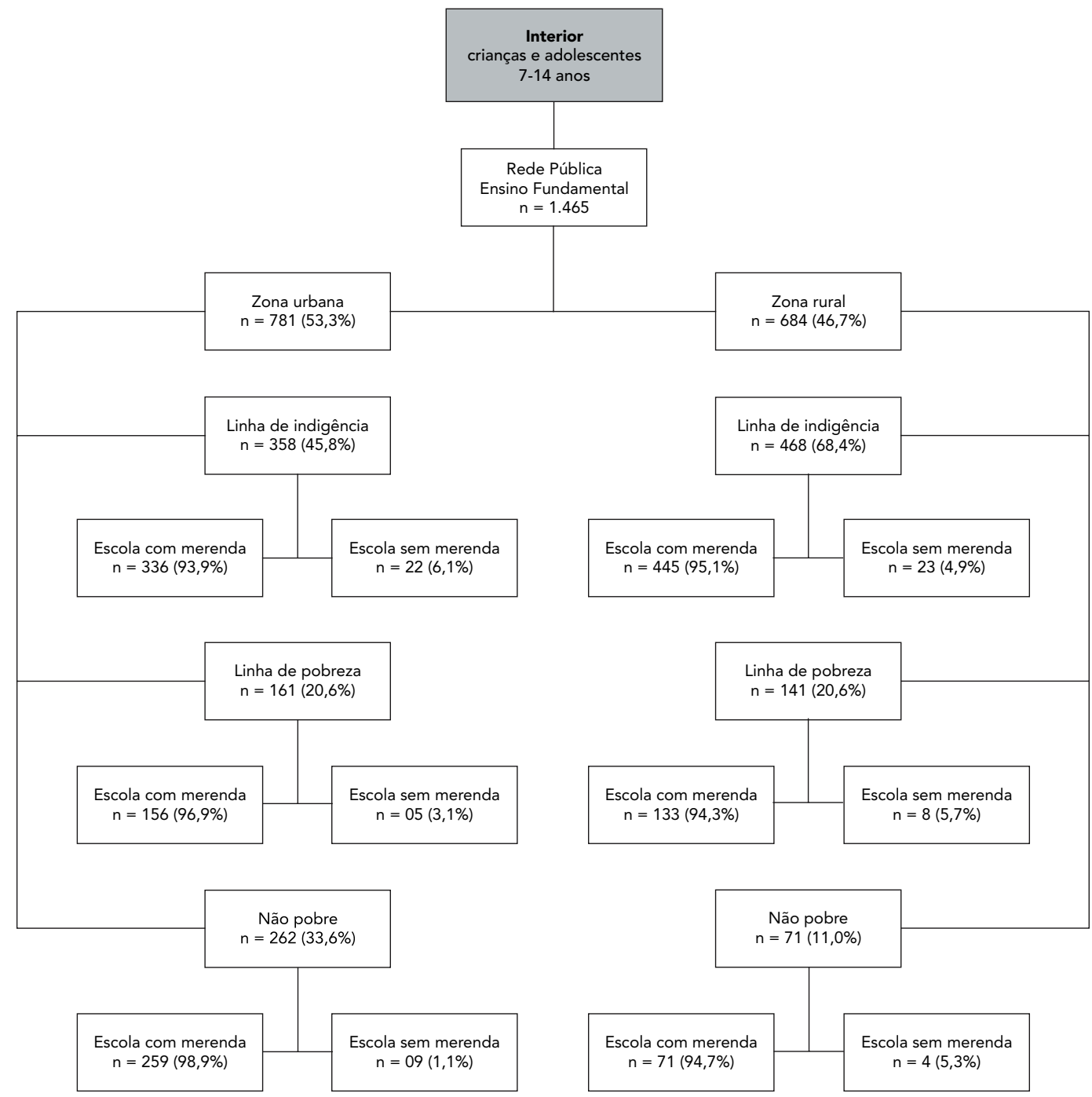

Fonte: trabalho de campo.

de, que se manteve praticamente inalterada ao longo do período ${ }^{11}$. Resultados similares foram encontrados em Cuiabá 16. Esse aspecto não foi avaliado no estudo de caso na Bahia.

\section{- Opinião dos beneficiários quanto à alimentação escolar}

No estudo de caso no interior da Bahia, buscouse a opinião dos pais sobre o programa e sua observação sobre a avaliação das refeições pelos fi- lhos. Segundo $67 \%$ dos respondentes, seus filhos consideravam boa a refeição servida na escola; para $25 \%$ destes as crianças gostavam de algumas preparações. Apenas 3\% dos entrevistados emitiram críticas à qualidade da refeição servida. A situação de pobreza do grupo estudado ficou evidente nas respostas que obtiveram maior percentual ("Bom, não tem alimentos em casa"; "Garantia de refeição na escola despreocupa os pais”). Apenas um grupo, minoritário, referiu-se ao programa como "um direito da criança" (0,5\%). 
Quadro semelhante foi encontrado em Salvador com $52 \%$ de aprovação e $27 \%$ de aceitação de apenas algumas preparações entre os escolares estudados. A maioria dos pais considerou que o programa era bom e que garantia uma refeição que eles não teriam condições de oferecer. Para $2 \%$ dos entrevistados em Salvador observou-se uma visão caritativa do programa, considerando-o como uma "bondade do governo", porém igual proporção reconheceu o programa como um "direito da criança".

A pesquisa nacional aferiu a opinião das crianças sobre os alimentos servidos na escola 13 . A proporção de alunos que considerou as refeições como "boa" e "muito boa", foi de $66 \%$ na zona rural e $69 \%$ na urbana; segundo as regiões a porcentagem que avaliou deste modo variou de $64 \%$ (Nordeste) a $76 \%$ (Sul).

\section{- Visibilidade do Conselho de Alimentação Escolar}

Na pesquisa realizada na Bahia, observou-se reduzida visibilidade do Conselho de Alimentação Escolar. Apesar de mais de 95\% das famílias informarem que os filhos tinham acesso ao programa, apenas $21 \%$ e $22 \%$ dos pais no interior e na capital, respectivamente, informaram saber da existência do Conselho. Dentre os que reconheceram a existência do Conselho de Alimentação Escolar, somente $20 \%$ referiram saber sobre suas atividades ou conhecer algum de seus membros.

A pesquisa nacional entrevistou membros de 324 Conselhos de Alimentação Escolar buscando conhecer a opinião dos pais sobre a importância dos mesmos no programa. Dentre eles, $43,5 \%$ consideraram como "muito grande" a importância, $41,7 \%$ "grande" e apenas $10,5 \%$ como "pequena" ou "muito pequena" (4,3\% não responderam). A justificativa dessas respostas apontou em primeiro lugar: "pela fiscalização" (39,2\%), que somada à resposta "ver a qualidade" (20,4\%), "definir melhor as diretrizes" (9,7\%) e "contribuir para aplicação correta dos recursos” (8,3\%) parecem demonstrar que os pais estão conscientes do papel que deve ser desempenhado pelo Conselho ${ }^{13}$.

\section{Conclusões}

Esta avaliação do PNAE foi oportuna, na medida em que, no momento do trabalho de campo, os municípios estavam implantando ou operacionalizando uma nova concepção de estrutura para o programa, contemplando a descentralização e a participação social. No que tange à estrutura do programa, observou-se que houve um significativo avanço na formalização do novo modelo municipalizado. Os Conselhos de Alimentação Escolar estavam criados na maioria dos municípios, atendendo assim aos princípios contidos nas diretrizes do programa.

No entanto, em relação ao processo de funcionamento dessas instâncias, dentro de um princípio democrático e descentralizado, observou-se que os avanços ainda eram modestos. O processo de descentralização parece ter gerado uma nova modalidade de "centralização" de poder no âmbito local, questão que foi levantada pelos entrevistados em vários momentos. Detectou-se ainda que a lógica da centralização do poder também vinha sendo observada no âmbito das escolas, nas quais, na maioria dos casos, as decisões sobre o programa ficavam sob a responsabilidade única dos diretores das unidades investigadas.

Ainda que os Conselhos de Alimentação Escolar estivessem constituídos, o processo de composição dos mesmos nem sempre representou, nas situações estudadas, um efetivo exercício de democracia. A maioria dos membros dos referidos conselhos era indicada pelo executivo municipal. Como visto, os conselhos não vinham exercendo as funções que normativamente lhes foram atribuídas e, também por isto, detinham baixa visibilidade. Observou-se também um insuficiente preparo dos membros dos conselhos para o desempenho do previsto. Na maioria dos casos, os membros entrevistados não reconheciam claramente o papel do Conselho de Alimentação Escolar e o seu próprio como representante de algum segmento.

Problemas foram relatados referidos à insuficiência de infra-estrutura, uma vez que a gestão descentralizada demanda investimentos em nível local para o provimento das instalações, equipamentos e do pessoal para o preparo e distribuição das refeições. Tal realidade se apresentou mais complexa na zona rural dos municípios.

No tocante a resultados, o estudo verificou que a cobertura do programa foi bastante significativa. No entanto, a focalização deixa a desejar no interior da Bahia, onde se encontrou maior proporção de escolas com PNAE entre aquelas freqüentadas por alunos de maior poder aquisitivo. A aceitabilidade da alimentação oferecida foi significativa, resultado esperado frente à situação de pobreza do conjunto de municípios avaliados. A questão da irregularidade na oferta do benefício ainda enfrentava problemas importantes, comprometendo sobremaneira a aspiração do programa efetivar-se como política social universal e um direito da criança, na perspectiva da promoção da segurança alimentar e nutricional. 


\section{Resumo}

Avaliou-se o Programa Nacional de Alimentação Escolar (PNAE), na perspectiva de estrutura-processo-resultado. A metodologia envolveu pesquisa documental e estudo de caso em 45 municípios no Estado da Bahia, Brasil; com entrevistas a getores, visita a 73 escolas e inquérito domiciliar envolvendo 3.367 crianças de 714 anos. Quanto à estrutura, foi analisada a evolução normativa do PNAE e alguns aspectos da infra-estrutura. Gestores referiram instalações e equipamentos inadequados para preparar e distribuir refeições em 28\% dos municípios. A municipalização estava presente em 93\% dos casos, havendo $20 \%$ já em processo de escolarização; porém, em quase 70\% das escolas havia repasse de gêneros alimentícios. A aceitabilidade da alimentação oferecida foi boa, resultado esperado frente à situação de pobreza da população estudada. Ainda que Conselhos de Alimentação Escolar estivessem constituídos, sua composição nem sempre representou um efetivo exercício democrático. Quanto a resultados, a cobertura foi expressiva - 95\%, contudo $77 \%$ dos entrevistados do interior e $39 \%$ da capital relataram não receber alimentação todo dia. A irregularidade observada na oferta diária comprometeu a aspiração do programa efetivar-se como política social universal e um direito da criança.

Segurança Alimentar; Estudantes; Avaliação de Programas e Projetos de Saúde

\section{Referências}

1. Brasil. Decreto $n^{\circ}$. 37.106, de 31 de março de 1955 Institui a Campanha de Merenda Escolar (CME), subordinada ao Ministério da Educação. Diário Oficial da União 1955; 2 abr.

2. Vasconcelos FAG. A política social de alimentação e nutrição no Brasil: acumulação de capital e reprodução da fome/desnutrição: do Estado Novo à Nova República [Dissertação de Mestrado]. João Pessoa: Centro de Ciências Humanas, Letras e Artes, Universidade Federal da Paraíba; 1988.

3. L'Abbate S. As políticas de alimentação e nutrição no Brasil: I - período de 1940 a 1964 . Rev Nutr 1988; 1:87-138.

4. L'Abbate S. As políticas de alimentação e nutrição no Brasil: II - a partir dos anos setenta. Rev Nutr $1989 ; 2: 7-54$

5. Brasil. Lei no ${ }^{\circ}$. 8.913, de 12 de julho de 1994. Dispõe sobre a municipalização da merenda escolar. Diário Oficial da União 1994; 13 jul.

\section{Colaboradores}

L. M. P. Santos e S. M. C. Santos foram responsáveis pela concepção do projeto, elaboração dos instrumentos, recrutamento e seleção da equipe, coleta, análise e interpretação dos dados. L. A. A. Santana, F. C. S. Henrique, R. P. D. Mazza, L. A. S. Santos e L. S. Santos participaram da elaboração dos instrumentos e da coleta de dados. Todas as autoras são responsáveis pela autoria e revisão final do texto.

\section{Agradecimentos}

Projeto financiado pela Financiadora de Estudos e Projetos (FINEP) com recursos do Banco Interamericano de Desenvolvimento (BID), processo número 64.96.054900.
6. Draibe SM. Descentralização das políticas sociais: o que ensinam as experiências recentes da merenda escolar, do dinheiro na escola e da TV Escola. Campinas: Núcleo de Estudos de Políticas Públicas, Universidade Estadual de Campinas; 1998. (Cadernos de Pesquisa, 36)

7. Santos LS. Avaliação do Conselho de Alimentação Escolar na implementação do Programa Nacional de Alimentação Escolar [Dissertação de Mestrado]. Salvador: Escola de Nutrição, Universidade Federal da Bahia; 2003.

8. Abreu M. Alimentação escolar na América Latina: programas universais ou focalizados/políticas de descentralização. Brasília: Instituto Nacional de Estudos e Pesquisas Educacionais; 1995. (Em Aberto, 67). 
9. Ministério de Desenvolvimento Social e Combate à Fome. Fome zero: balanço dos programas e ações. Brasília: Ministério de Desenvolvimento Social e Combate à Fome; 2005.

10. Santos SMC, Santos LMP. Avaliação de políticas publicas de segurança alimentar e combate à fome. 1 - Abordagem metodológica. Cad Saúde Pública 2007; 23:1029-40.

11. Santos LMP, Araújo MPN, Martins MC, Veloso IS, Assunção MP, Santos SMC. Avaliação de políticas públicas de segurança alimentar e combate à fome no período 1995-2002. 2 - Programa de Alimentação do Trabalhador. Cad Saúde Pública 2007; 23:1931-45.

12. Martins MC, Santos LMP, Santos SMC, Araújo MPN, Lima AP, Santana LAA. Avaliação de políticas públicas de segurança alimentar e combate à fome no período 1995-2002. 3 - O Programa Nacional de Controle da Deficiência de Vitamina A. Cad Saúde Pública 2007; 23:2081-93.

13. Ministério da Educação e do Desporto. Avaliação do impacto distributivo e elaboração de sistemática de monitoramento do PNAE. http://www.fnde. gov.br/apresentacoes/apresentacao01/sld064.htm (acessado em 02/Abr/2006).

14. Brasil. Medida Provisória no. 1.784, de 14 de dezembro de 1998. Dispõe sobre o repasse de recursos financeiros do Programa Nacional de Alimentação Escolar, institui Programa Dinheiro Direto na Escola, e dá outras providências. Diário Oficial da União 1998; 15 dez.
15. Vianna RPT, Tereso MJA. Análise do programa de merenda escolar em Campinas. Revista Cadernos de Debate 1997; 5:46-76.

16. Spinelli MAS, Canesqui AM. Descentralização do Programa de Alimentação Escolar em Cuiabá: 1993-1996. Rev Nutr 2004; 17:151-65.

17. Pipitone MAP, Ometto AMH, Silva MV, Sturion GL, Furtuoso MCO. Atuação dos conselhos municipais de alimentação escolar na gestão do programa de alimentação escolar. Rev Nutr 2003; 16:143-54.

18. Contreras O, Bennett V. National solidarity in the Northern borderlands: social participation and community leadership. In: Cornelius W, Craig A, Fox J, editors. Transforming state-society relations in Mexico: the national solidarity strategy. San Diego: Center for U.S. Mexican Studies, University of California; 1994. p. 281-305.

19. Ministério da Educação. Relatório do Censo Escolar PNAE. Sistema de Ações de Assistência Educacional (SAE) da Diretoria de Ações Educacionais (DIRAE) do FNDE. Brasília: Ministério da Educação; 2002.

Recebido em 01/Set/2006

Versão final reapresentada em 25/Abr/2007

Aprovado em 02/Mai/2007 